\title{
Giants on coke
}

\section{George Rousseau learns about the impact of cocaine on physicians Sigmund Freud and William Halsted.}

$\mathrm{T}$ wo eminent physicians became addicted to cocaine in the 1880s: Sigmund Freud, the founder of psychoanalysis, and William Halsted, the great US surgeon and early advocate of the aseptic technique. Each developed a dependence while seeking ways to reduce their anxieties about their careers and private lives. Now, two books explore how the addiction altered each man's life, personally and professionally.

Medical historian Howard Markel explores these parallel lives in An Anatomy of Addiction, and David Cohen in Freud on Coke valiantly interprets Freud's conscious and unconscious states without obeisance to canonical biography. Both books are gripping for their revelations about private lives in public contexts - in these cases, the lives of driven men determined to become worldclass figures while under the influence.

As Markel notes, Freud is thought to have started taking cocaine as a young researcher at the Vienna General Hospital in the early 1880 s, to relieve nasal lesions. Cocaine known as coca at the time - was considered a miracle drug. Its extraordinary physiological powers were the topic, in 1885, of Freud's first medical treatise, Über Coca. Freud was then scraping together a living, insecure about his medical competence and his strained relationship with his politically radical father, and trying to find a niche for himself. Cocaine assuaged his stress, but addiction blinded him to the drug's medical use as an anaesthetic, even though he was convinced of its use in treating morphine addiction.

Halsted, Markel shows, became hooked on cocaine while criss-crossing continents. He sailed on ocean liners to Europe, studied medicine in Germany and was so restless that he sometimes disappeared from work and public life. In 1886, his addiction landed him in the Butler Hospital, a psychiatric institute in Providence, Rhode Island, where he was treated and released. But as his star rose he continued to take the drug, even while a leading professor at the Johns Hopkins University School of Medicine, the country's premier

An Anatomy of Addiction: Sigmund Freud, William Halsted, and the Miracle Drug Cocaine HOWARD MARKEL Pantheon: 2011. 352 pp. $\$ 28.95$

Freud on Coke DAVID COHEN Cutting Edge Press: 2011. 200 pp. £14.99
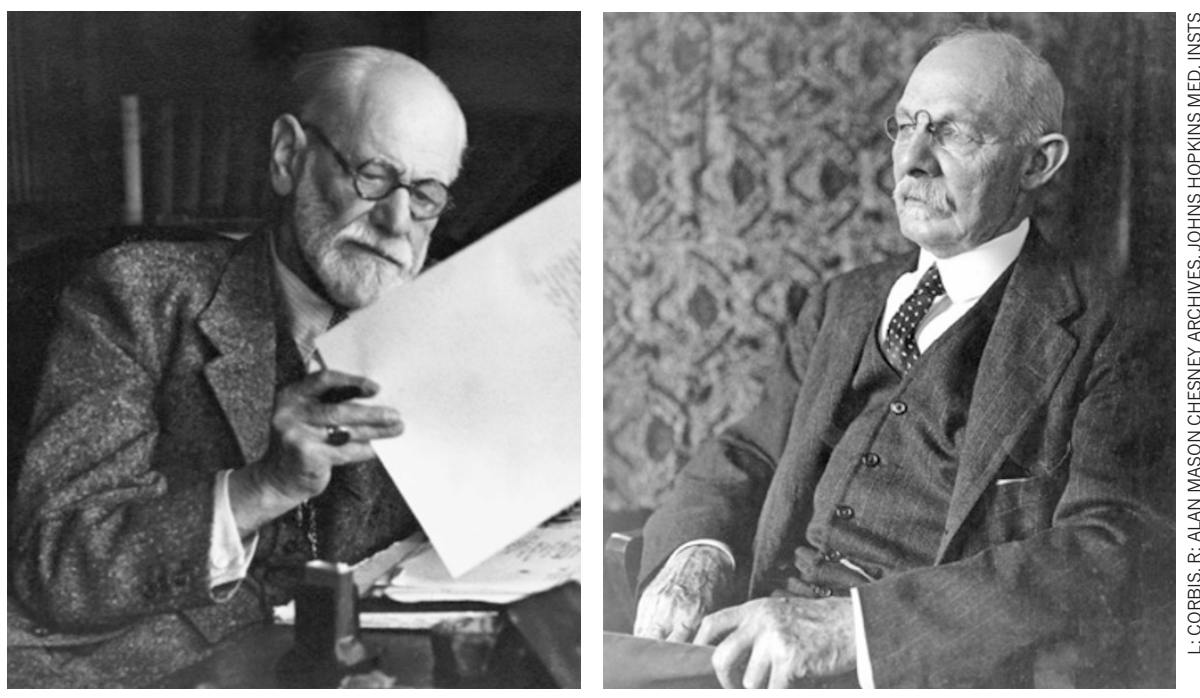

Psychologist Sigmund Freud (left) and surgeon William Halsted took cocaine to relieve anxiety.

medical school in Baltimore, Maryland.

Ambition and anxiety were not the only factors favourable to the development of a habit. Coca was viewed as harmless in the nineteenth century, and, as scientific researchers, Freud and Halsted had access to large quantities. They were among its first user-victims. Both saw their enslavement as just another moral defect that could be remedied by routine and prayer. But cocaine use fundamentally affected their relationships with patients, colleagues, family and friends, and was detrimental to their health. Each man's 'coke story' also raises the question of whether either would have been able to conquer a new province of knowledge without the drug.

Certainly, Freud's anxieties figure prominently in the famous 1895 dream 'Irma's injection', which became a pillar of his psychoanalytic theory. Both Markel and Cohen consider the episode to be key to understanding his addiction. The dream reflected a bizarre incident in Freud's life. His medical accomplice, Wilhelm Fliess, with Freud's blessing, had attempted to cure Freud's patient Emma Eckstein of her 'nasal reflex neurosis' by operating on her nose. Fliess botched the operation. In the dream, Irma (Emma) reproaches Freud for her condition, and he blames it on an injection given by a friend. In real life, Freud was so anxious about the effect of this case on his reputation that he took even more cocaine, affecting his marriage and other relationships.

Halsted also struggled with personal relationships. Yet his addiction probably accelerated his already formidable drive, and may even have helped him to formulate insights on the urgent need for surgical antisepsis.

Both men learned to suppress and manage their addictions after making their names. Late in life, Freud - who seemed to thrive on contradiction and hypocrisy - took giant steps to cover up traces of his habit, because the truth might have cast a shadow over his central theories. Most of Halsted's hospital colleagues knew of his addiction, but nothing was said - and the man himself, as is clear in Markel's book, could not countenance the truth.

Markel brilliantly describes the paradoxes of the two lives. Cohen adroitly teases out the nuances of the Irma episode. There is also a subplot to Cohen's biography: the resistance the writer encountered from some specialists while researching his book. The reputation of the Viennese enigma remains unassailable among official biographers, but with every passing year, the weight of evidence points more clearly to the high price that Freud and his intimates paid for the 'cocaine years'.

George Rousseau is a professor of history at the University of Oxford and co-director of its Centre for the History of Childhood, Oxford, OX1 4AU, UK.

e-mail:george.rousseau@magd.ox.ac.uk 